\title{
Anomalous quasi-stationary planetary waves over the Antarctic region in 1988 and 2002
}

\author{
A. V. Grytsai, O. M. Evtushevsky, and G. P. Milinevsky \\ National Taras Shevchenko University of Kyiv, Ukraine \\ Received: 19 January 2007 - Revised: 13 July 2007 - Accepted: 25 July 2007 - Published: 28 May 2008
}

\begin{abstract}
Anomalies in the Antarctic total ozone and amplitudes of the quasi-stationary planetary waves in the lower stratosphere temperature during the winter and spring of 1988 and 2002 have been compared. Westward displacement of the quasi-stationary wave (QSW) extremes by $50^{\circ}-$ $70^{\circ}$ relative to the preceding years of the strong stratospheric polar vortex in 1987 and 2001, respectively, was observed. A dependence of the quasi-stationary wave ridge and trough positions on the strength of the westerly zonal wind in the lower stratosphere is shown. Comparison of the QSW amplitude in the lower stratosphere temperature in July and August shows that the amplitude distribution with latitude in August could be considered as a possible indication of the future anomalous warming in Antarctic spring. In August 2002, the QSW amplitude of $10 \mathrm{~K}$ at the edge region of the polar vortex $\left(60^{\circ} \mathrm{S}-65^{\circ} \mathrm{S}\right)$ preceded the major warming in September, whereas in August 1988, the highest $7 \mathrm{~K}$ amplitude at $55^{\circ} \mathrm{S}$ preceded the large warming in the next months. These results suggest that the peak value of the lower stratosphere temperature QSW amplitude and the peak latitudinal position in late winter can influence the southern polar vortex strength in spring.
\end{abstract}

Keywords. Atmospheric composition and structure (Pressure, density, and temperature) - Meteorology and atmospheric dynamics (Middle atmosphere dynamics; Waves and tides)

\section{Introduction}

In late September 2002 the first major stratospheric sudden warming was observed in the Antarctic region (Varotsos, 2002). The ozone hole area was considerably smaller than in previous years and split into two parts on 24-25 September (Allen et al., 2003; Varotsos, 2003a; Varotsos, 2004; Baldwin

Correspondence to: G. P. Milinevsky

(gennadim@gmail.com) et al., 2003; see also the special issues of Journal of Atmospheric Sciences, 2005, vol. 62, no. 3, and International Journal of Remote Sensing, 2005, vol. 26, no. 16). This event, caused by the large-scale dynamical processes in the atmosphere (Charlton et al., 2005), resulted in the strong reduction of chemical ozone losses over Antarctica. Although up to the time of the major warming the losses inside the polar vortex were similar to previous years, the unusual dynamics led to an $\sim 250$ DU increase in the total ozone near the pole in late September (Hoppel et al., 2003). Southward of $60^{\circ} \mathrm{S}$ the October mean total ozone content (TOC) in 2002 exceeded the climatology for 1990-2001 up to 120 DU and the entire Southern Hemisphere average exceeded the climatology by $2.5 \%$ (Stolarski et al., 2005).

The unusual behavior of the ozone hole during spring 2002 was preconditioned by enhanced planetary wave activity throughout the winter months, which weakened the polar vortex and warmed the stratosphere (Allen et al., 2003; Newman and Nash, 2005; Scaife et al., 2005), possibly setting the stage for the major stratospheric warming in late September (Randall et al., 2005). An important role of wave numbers 1 and 2 in the major warming was demonstrated by Charlton et al. (2005), Krüger et al. (2005), Newman and Nash (2005), Scaife et al. (2005). It is emphasized that the smaller size of the ozone hole, the lower ozone loss, and the amplification of wave activity observed in 2002 partly resembled that for 1988 (Varotsos, 2002, 2003a, b; Allen et al., 2003; Baldwin et al., 2003).

The event of 1988 did not represent major warming and it was classified rather as a large or strong sudden stratospheric warming (Kanzawa and Kawaguchi, 1990; Varotsos, 2003a). The stratospheric warmings of 1988 and 2002 showed clear spring anomalies in the zonal mean total ozone (Jadin and Vargin, 2004), amplitude of the zonal wave in TOC (Grytsai et al., 2005) and mean zonal wind and upward EP flux in the lower stratosphere (Hio and Yoden, 2005; Scaife et al., 2005).

Published by Copernicus Publications on behalf of the European Geosciences Union. 

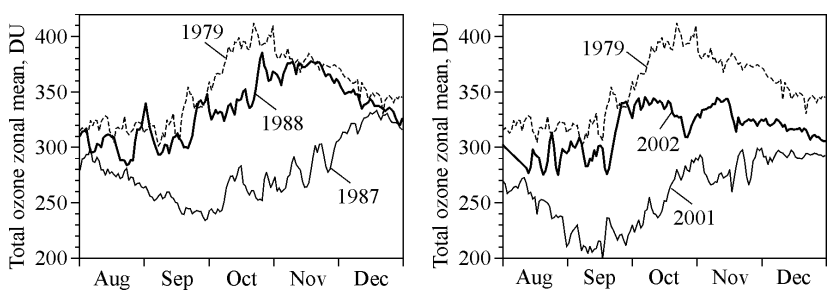

Fig. 1. (a) Variations in the daily zonal mean in the total ozone at $65^{\circ} \mathrm{S}$ during August-December 1988 (thick line) and 1987 (thin line) from the TOMS measurements. (b) The same for 2002 and 2001 (thick and thin lines, respectively). Dashed lines denote the pre-ozone hole year 1979 .

Planetary waves in the Southern Hemisphere have a dominant zonal harmonic of wave number 1 and its stationary component (quasi-stationary in real atmosphere) prevails over the higher harmonics (Wirth, 1993; Quintanar and Mechoso, 1995). Wave 1 causes displacement of the stratospheric polar vortex relative to the pole. This forms zonal asymmetry in the stratospheric zonal flow and persistent asymmetry can influence the polar vortex strength and stability. The energy introduced in the stratosphere by a quasistationary wave with the dominating zonal wave number 1 can contribute to a weakening of the polar vortex.

Further comparison of 1988 and 2002 may shed light on the cause of the major warming (Allen et al., 2003) and we analyze some of their similarities and distinctions in later sections. We focus on the quasi-stationary waves and show that they can contribute to preconditioning the anomalous warming in the Southern Hemisphere. To look for the earliest indications of an anomalous evolution in the winter stratosphere, the comparison of the monthly means for July and August was made using the total wave number QSW amplitude in the stratospheric temperature. To see the effects of the anomalous warming on the mean state of the spring stratosphere, the September-November means in the total ozone and zonal wind are considered. Section 2 gives briefly the data description. A seasonal change in the TOC zonal mean is considered in Sect. 3. Quasi-stationary planetary wave anomalies are analyzed in Sect. 4 (QSW zonal structure) and Sect. 5 (QSW amplitude distribution with latitude). Discussion and conclusions are presented in Sect. 6.

\section{Data}

Total ozone data were used from Total Ozone Mapping Spectrometer (TOMS) measurements during 1979-2005 (Version 8 , http://toms.gsfc.nasa.gov). It is known that TOC and the lower stratosphere temperature are highly correlated (Wirth, 1993). Due to the ozone data gap in 19931995 and the absence of TOMS measurements at high latitudes during polar night, the lower stratospheric temperature at the $100 \mathrm{hPa}$ level was obtained from the National
Centers for Environmental Prediction - National Center for Atmospheric Research (NCEP-NCAR) reanalysis data (http: //www.cdc.noaa.gov/cdc/reanalysis). The seven latitude circles with the step of $5^{\circ}$ within the interval $50^{\circ} \mathrm{S}-80^{\circ} \mathrm{S}$ have been selected. This zone includes the edge and inner regions of the ozone hole and adjacent middle latitudes, where a high level of the planetary wave activity is usually observed during the southern winter-spring seasons. Zonal wind velocity for individual years was obtained from NCEP-NCAR reanalysis data.

\section{Seasonal change in the total ozone zonal mean}

First, we consider the features of the seasonal variations in TOC under conditions of weak (1988 and 2002) and strong (1987 and 2001) stratospheric polar vortex in the Southern Hemisphere. The latitude circle $65^{\circ} \mathrm{S}$ is chosen to present the edge region of the polar vortex. In this region a combined effect of polar ozone loss, ozone hole size variations and planetary wave influence could be observed in the TOC data. This region is sensitive to the earliest stage of warming. Newman and Nash (2005) had shown that during the entire winter of 2002 (June-August), the temperatures at the vortex edge region (near the polar night jet axis, $65^{\circ} \mathrm{S}, 50 \mathrm{hPa}$ ) were higher than normal. They noted that warming in this region is directly controlled by the planetary waves which propagate upward from the troposphere into the stratosphere.

Figure 1 shows the changes in the TOC zonal mean at $65^{\circ} \mathrm{S}$ during August-December (in the winter months of June and July, TOMS does not measure the total ozone at this latitude). It is seen that the zonal means in 1988 and 2002 (thick lines) are significantly higher than in the preceding 1987 and 2001 (thin lines), respectively, during the entire 5-month interval (see also the comparison in Grytsai, 2005, which includes the curves for 1989 and 2003 coinciding closely to 1987 and 2001, respectively). The spring ozone minimum, which is a typical feature of the TOC seasonal change at high and polar southern latitudes since the early 1980s (as it is seen from the curves for 1987 and 2001 in Fig. 1) is absent in 1988 and 2002. The 5-month average values of zonal mean in 1988 and 2002 exceed those for the preceding years by $57 \mathrm{DU}$ and $56 \mathrm{DU}$, respectively.

One can see the distinctions between the manifestations of the strong/weak vortex conditions, on the one hand, and the situation in the pre-ozone hole year 1979, on the other hand (dashed lines in Fig. 1). This year is the first winterspring season presented in the TOMS data sets. It is seen from Fig. 1 that each of the anomalous years 1988 and 2002 (thick curves) are in between 1979 and preceding the years of a strong vortex in 1987 and 2001, respectively, but they both tend to be closer to 1979 .

Except for October, in 1988, the seasonal course of the TOC zonal mean at $65^{\circ} \mathrm{S}$ approaches closely the pre-ozone hole seasonal course (Fig. 1a). For example, between 
1 August and 15 September 1979, the zonal mean averaged nearly $320 \mathrm{DU}$, whereas in 1988 and 2002 the levels of $\sim 300$ DU and $\sim 290$ DU, respectively, were observed. This common feature could probably be attributed to the similar influence of the dynamical processes on the polar vortex edge in late winter and early spring 1988 and 2002. Even in the absence of the sharp increase in late September 2002 (Fig. 1b, thick line), it is unlikely that the TOC level would be decreased below $300 \mathrm{DU}$ in October, hence the anomalously high total ozone during August-December would remain this year.

It should be noted that the seasonal maximum of the total ozone in spring 1979 (October-November, see dashed line in Fig. 1) displays the natural annual cycle of the total ozone in the Southern Hemisphere (WMO, 1999). Figure 1a shows a partial recovery of this maximum in November 1988. Due to the chemical ozone losses, the spring ozone maximum in the Antarctic region was replaced by a minimum. This is confirmed, for example, by Fig. 4-24 in WMO (1999), which shows that at Faraday/Vernadsky the spring maximum in November was observed during 1957-1975 but the spring minimum in September-October appeared since 1985. The tendency toward the seasonal course recovery shows that in 1988 and 2002 the dynamical processes counteracted the ozone chemical destruction. However, due to the significant long-term ozone depletion in Antarctica, even the extremely high planetary wave activity in 2002 did not fully cause the normal spring maximum to appear (Fig. 1b, thick line). So, the total ozone increase in 1988 and 2002 does not mean that the ozone layer recovered but shows an ability of the dynamical factor to reduce the chemical ozone losses. Figure 1 shows that anomalous stratospheric warming can be identified in the TOC zonal mean at $65^{\circ} \mathrm{S}$ as early as August.

\section{QSW zonal structure}

In this section the quasi-stationary zonal distribution of the total ozone is considered. The 3-month mean longitudinal distributions for September-November at the latitude $65^{\circ} \mathrm{S}$ are shown in Fig. 2. The same years as in Fig. 1 are presented. Each of the curves has one maximum and one minimum, displaying a main contribution of the stationary wave 1.

Previous study of the extreme positions at $65^{\circ} \mathrm{S}$ had revealed the long-term eastward shift of the zonal minimum (Grytsai et al., 2005). The shift velocity is about $24^{\circ} /$ decade. The zonal wave trough position in Fig. 2 shows a noticeable westward shift in anomalous 1988 and 2002 (thick lines) relative to typical 1987 and 2001 (thin lines), by $50^{\circ}$ and $70^{\circ}$, respectively. The wave ridge westward shift was $60^{\circ}$ and $15^{\circ}$, respectively. The observed westward shift of the zonal wave has an opposite direction relative to the long-term tendency of the eastward shift. As in the TOC zonal means, the QSW
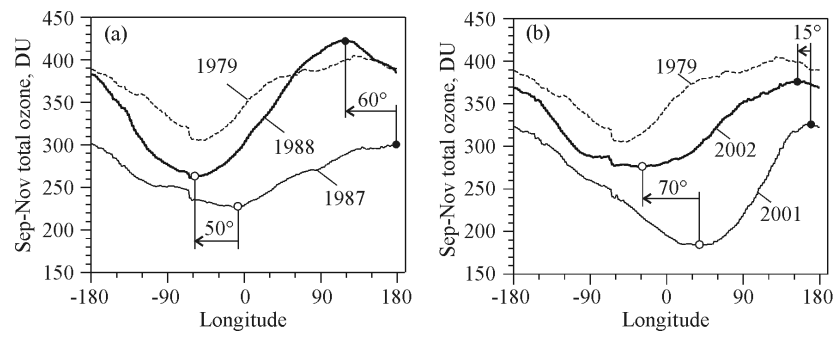

Fig. 2. September-November averaged longitudinal distribution of total ozone at $65^{\circ} \mathrm{S}$ for the same years and with the same indications as in Fig. 1. Open and closed circles mark the longitudinal positions of zonal minimum and maximum, respectively. Arrows indicate the westward longitudinal displacements of the weak vortex extremes relative to the strong vortex ones.

ridge/trough positions in 1988 and 2002 approach those in 1979 (dashed lines in Fig. 2).

The observed QSW structure change is associated with a westerly wind strength. Under the strong vortex conditions (1987 and 2001), the quasi-stationary wave extremes tend to be placed far to the east in comparison with the weak vortex conditions (1988 and 2002). This suggests a direct correlation between zonal wind velocity and the position of the QSW extremes.

To examine this possibility the September-November mean zonal wind velocity was considered. Climatologically, the spring maximum of the stratospheric jet flow lays at about $60^{\circ} \mathrm{S}$ (Kallberg et al., 2005, Fig. C2). However, during the compared springs the zonal wind extremes were located closer to the $55^{\circ} \mathrm{S}$ latitude (Fig. 3, dashed circles).

The longitudinal shift of the wind extremes has a similar tendency to those in the total ozone in Fig. 2. This is seen from Fig. 3, where an eddy component of the SeptemberNovember mean zonal wind presents the longitudinal position of the wind extremes (dashed radial lines) and their westward shift (arrows) in the weak vortex conditions relative to the strong vortex conditions.

The vertical wind profiles have been created using pressure level data by a NCEP/NCAR reanalysis. As is seen from Figs. 2 and 3, the quasi-stationary total ozone and zonal wind extremes tend to be placed around the longitudes $0^{\circ} \mathrm{E}$ and $180^{\circ} \mathrm{E}$. These two points on the $55^{\circ} \mathrm{S}$ latitude circle have been chosen to estimate both the wind velocity difference in weak/strong vortex and the wind zonal asymmetry.

Figure 4 shows clearly the difference in the wind velocity under the weak and strong vortex conditions. Moreover, at the stratosphere altitudes between $200 \mathrm{hPa}$ (dashed horizontal line) and $10 \mathrm{hPa}$ the difference increases significantly. Approaching the highest pressure level of $10 \mathrm{hPa}$, the wind velocities in 1988 (2002) become about two (three) times lower than in 1987 (2001). This can be seen from Fig. 4b, c by the average difference between the velocity ranges marked by the red and blue curves for the weak and strong vortex 
NCEP/NCAR reanalysis

Eddy u-wind, $30 \mathrm{mb}$

Sep-Nov mean
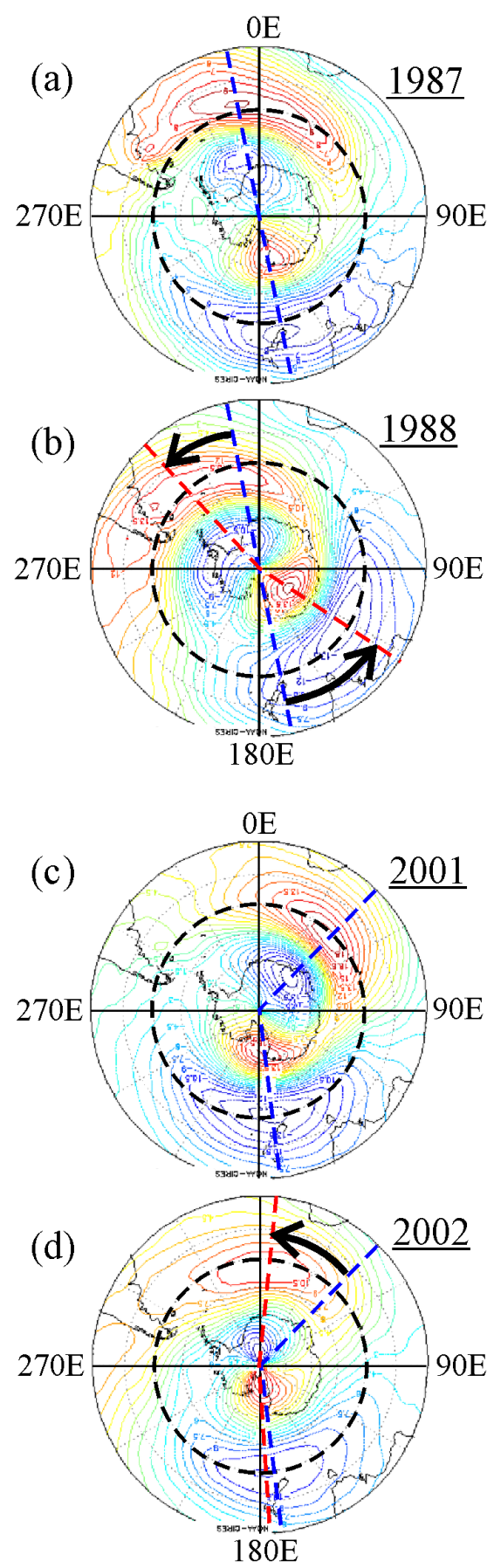

Fig. 3. Position of the zonal anomalies (dashed radial lines) of the September-November mean zonal wind under conditions of the strong $(\mathbf{a}, \mathbf{c})$ and weak $(\mathbf{b}, \mathbf{d})$ stratospheric polar vortex. NCEP/NCAR reanalysis data for the pressure level of $30 \mathrm{hPa}$ to the south of $30^{\circ} \mathrm{S}$. (warmer and colder polar stratosphere), respectively. Results of this comparison give the rough estimate of the distinctions in the stratospheric dynamics, which are denoted qualitatively by weak and strong polar vortices. The year 1979 (Fig. 4a) takes an intermediate position between the typical (1987 and 2001) and anomalously low (1988 and 2002) intensity of the zonal wind.

Zonal wind features demonstrated by Figs. 3 and 4 could mean that in the interannual variations the zonal wind extreme positions depend on the wind strength: the stronger zonal wind is associated with the extreme positions, which are farther to the east, than under the weaker zonal wind. This tendency possibly displays some property of the quasistationary wave interaction with the zonal flow, which needs further study. In turn, the positions of the total ozone extremes can be a simple consequence of the zonal wind pattern.

Figure 4 demonstrates that the clear wind velocity difference exists not only in the weak/strong vortex comparison but also in the wind zonal asymmetry observed in the individual years. Typically, at the longitude $0^{\circ} \mathrm{E}$ the stratospheric zonal wind is much stronger than at $180^{\circ} \mathrm{E}$ (solid and dashed curves, respectively, in Fig. 4). Also, Fig. 3 shows a closeness of the wind extreme longitudes to the total ozone extreme longitudes in Fig. 2. Ozone minimum is located near the wind maximum and vice versa.

An increase in the wind asymmetry with altitude, especially significant in 2001 and 2002 (Fig. 4c), can indicate a possible cause of this relationship. Because a meridional Brewer-Dobson circulation has its descending branch at the middle stratosphere altitudes, the strong/weak zonal wind can restrict/favour ozone descent. The possible ozone blowing/accumulation in the opposite longitudinal sectors, due to zonal wind asymmetry, should be examined in more detail, including the pressure level data some higher than $10 \mathrm{hPa}$ and modeling the stratospheric circulation with the strongly asymmetric zonal wind.

\section{QSW amplitude: meridional distribution}

The anomalous change in total ozone in 1988 and 2002 begins in August (see Fig. 1). Because the TOMS measurements are not carried out at high latitudes during winter months, we consider the temperature distribution at the $100 \mathrm{hPa}$ pressure level (about $16 \mathrm{~km}$ ) in July and August. The NCEP-NCAR reanalysis data for latitudes between $50^{\circ} \mathrm{S}$ and $80^{\circ} \mathrm{S}$ are analyzed. The monthly mean amplitude of the quasi-stationary wave was estimated by zonal distribution of the temperature at individual latitude circles with the $5^{\circ}$ step. The amplitude was calculated as a half difference between temperature zonal maximum and minimum and, hence, this value presents the zonal anomalies of the total wave numbers. Due to the dominance of the wave 1 contribution, the quasi-stationary wave in the monthly mean temperature has 


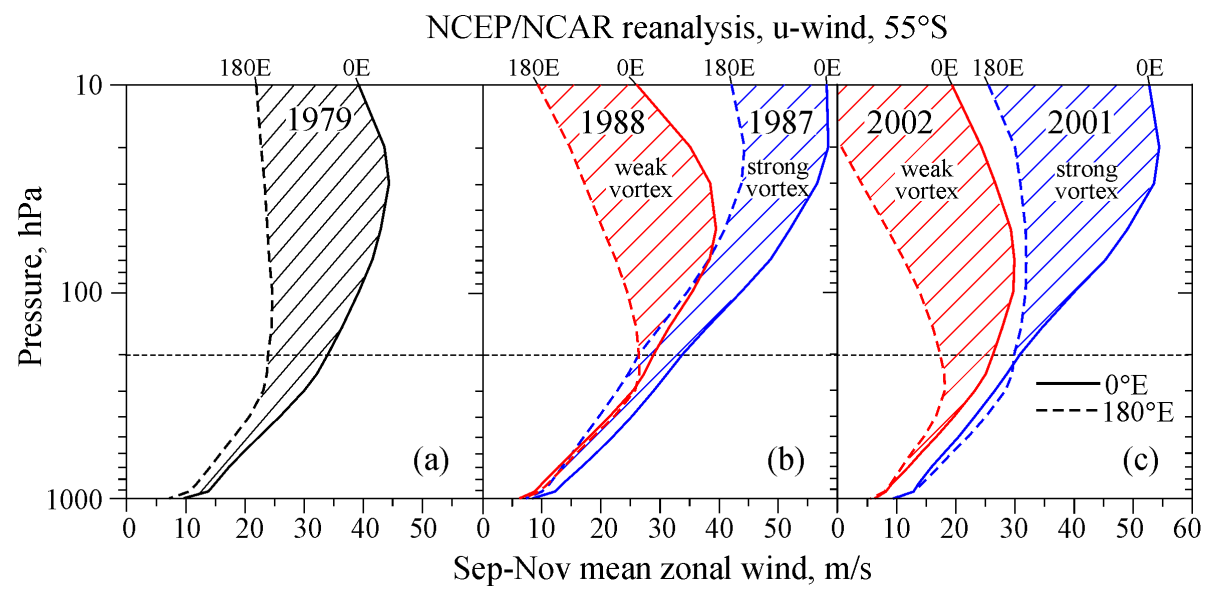

Fig. 4. Vertical profiles of the September-November mean zonal wind in 1979 (a), 1987/1988 (b) and 2001/2002 (c). To illustrate a degree of the wind zonal asymmetry, the two opposite points of the latitude circle $55^{\circ} \mathrm{S}$ are presented, $0^{\circ} \mathrm{E}$ (solid curves) and $180^{\circ} \mathrm{E}$ (dashed curves). The weak and strong vortex years are marked by the red and blue lines, respectively.

the zonally asymmetric structure, similar to those in the total ozone and zonal wind (Fig. 2 and Fig. 3, respectively).

Climatologically, July and August show almost an identical latitudinal change in the QSW amplitude (Fig. 5), especially if anomalous 1988 and 2002 are excluded from averaging for August in Fig. 5b. The level of the amplitude interannual variability shown by the standard deviation bars in Fig. 5 is also the same in such a comparison version of July and August (Fig. 5a and b, respectively). Taking into account the two anomalous years, the higher level of standard deviation is seen in August from Fig. 5c with the same meridional profile of amplitude as in Fig. 5b.

In September the QSW amplitude increases significantly and becomes twice as much as in August at $60^{\circ} \mathrm{S}$ (Fig. $5 \mathrm{~d}$ in comparison with Fig. 5b). Figure 5 demonstrates that typically the latitudinal course of stationary planetary wave amplitude at $50^{\circ} \mathrm{S}-80^{\circ} \mathrm{S}$ is weakly disturbed in the two winter months (July and August) in comparison with early spring (September). This allows for the examination of the interannual variations of the QSW amplitude in winter with respect to possible indications of the following anomalous spring events.

The variations of the meridional profiles of the QSW amplitude in 1979-2006 show that the anomalies of 1988 and 2002 appeared in August only (Fig. 6). Both 1988 and 2002 do not stand out against a background of the interannual amplitude variations in July (Fig. 6a). In contrary, the amplitudes in August exhibit a clear increase in 1988 and 2002 (Fig. 6b).

The obtained results show the possibility to predict the type of ozone hole evolution using a meridional distribution of the QSW amplitude in the lower stratosphere temperature. First, the average of August's amplitudes of about $4 \mathrm{~K}$ (Fig. 5b, c) indicates a typical future development of an ozone hole in spring with a typical level of ozone loss ob- served in the strong vortex conditions. Second, the maximal amplitude values of about $7 \mathrm{~K}$ (10 K), as in 1988 (2002) (Fig. 6b), could predetermine the conditions of future large (major) stratospheric warming with low (lowest) ozone loss.

Figure $6 \mathrm{~b}$ shows that an amplitude increase at the subantarctic latitudes $50^{\circ} \mathrm{S}-60^{\circ} \mathrm{S}$ only (the case of 1988) is insufficient to provide major warming, which is accompanied by an amplitude increase in the whole latitude range of $50^{\circ} \mathrm{S}-80^{\circ} \mathrm{S}$ with a maximum level of $10 \mathrm{~K}$ (the case of 2002).

\section{Discussion and conclusions}

Anomalous stratospheric warmings of 1988 and 2002 in the Southern Hemisphere have been analyzed. A comparison was made not only between 1988 and 2002 but also between these years of weak polar vortices and the preceding years of strong polar vortices, 1987 and 2001, respectively. As a background, the conditions of the pre-ozone hole year 1979 were considered.

Analysis includes the characteristics of the southern stratosphere related to the stratospheric warming: total ozone, zonal wind and air temperature. Results show that the TOC zonal mean at the edge region of the polar vortex $\left(65^{\circ} \mathrm{S}\right)$ had similar seasonal changes in 1988 and 2002. An early increase in the TOC level since August was observed in both cases (Fig. 1). This is associated with the anomalous winter warming of the vortex edge region due to a high level of planetary wave activity (Newman and Nash, 2005).

It is worth taking note that the seasonal change in the TOC zonal mean in this region is distinctly strong in the pre- and post-early-1980s period. Due to a chemical ozone loss, the former climatological spring maximum in November up to 400 DU was replaced by a spring minimum in September- 


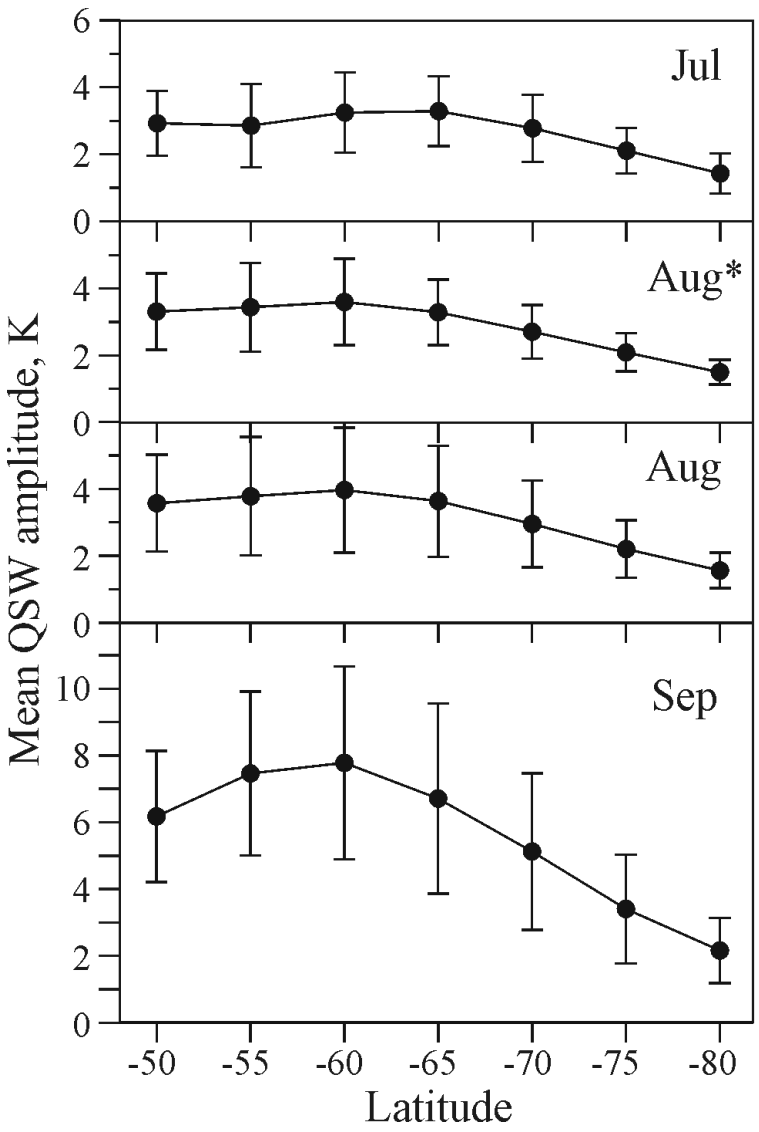

(b)

Fig. 5. Meridional structure of the QSW amplitude in the stratospheric temperature at $100 \mathrm{hPa}$ averaged over 1979-2005, for (a) July, (b) August with exception of anomalous 1988 and 2002, (c) August for total data and (d) September.

October at the level of 200-250 DU (Fig. 1, see also WMO, 1999, Figs. 4-24). Curves for 1988 and 2002 in Fig. 1 approach the 1979 ones, indicating a tendency to recover the normal seasonal course observed before the 1980s. Figure 1 also shows that this tendency can be detected in the TOMS data at $65^{\circ} \mathrm{S}$ since August.

It was shown by Hoppel et al. (2003) that inside the vortex the chemical ozone loss in 2002 was similar to previous years, up to late September (before the major warming), and was reduced by about $20 \%$ only through early October. This is evidence that chemical ozone destruction occurred with a typical intensity but it was limited in the spatial and time scales by dynamical activity: the ozone hole was smaller and its duration was shorter than usual. Besides, the polar vortex was larger distorted by the planetary waves both in 1988 and 2002, providing the extra-vortex air transport to the higher latitudes. Hence, the tendency of the spring ozone maximum to recover in Fig. 1 can be explained by dynamical causes. Additionally, significant weakening of the zonal wind in the middle stratosphere (Fig. 4b, c) could favour the ozone accumulation outside the vortex through the Brewer-Dobson circulation, as was assumed in Sect. 4.
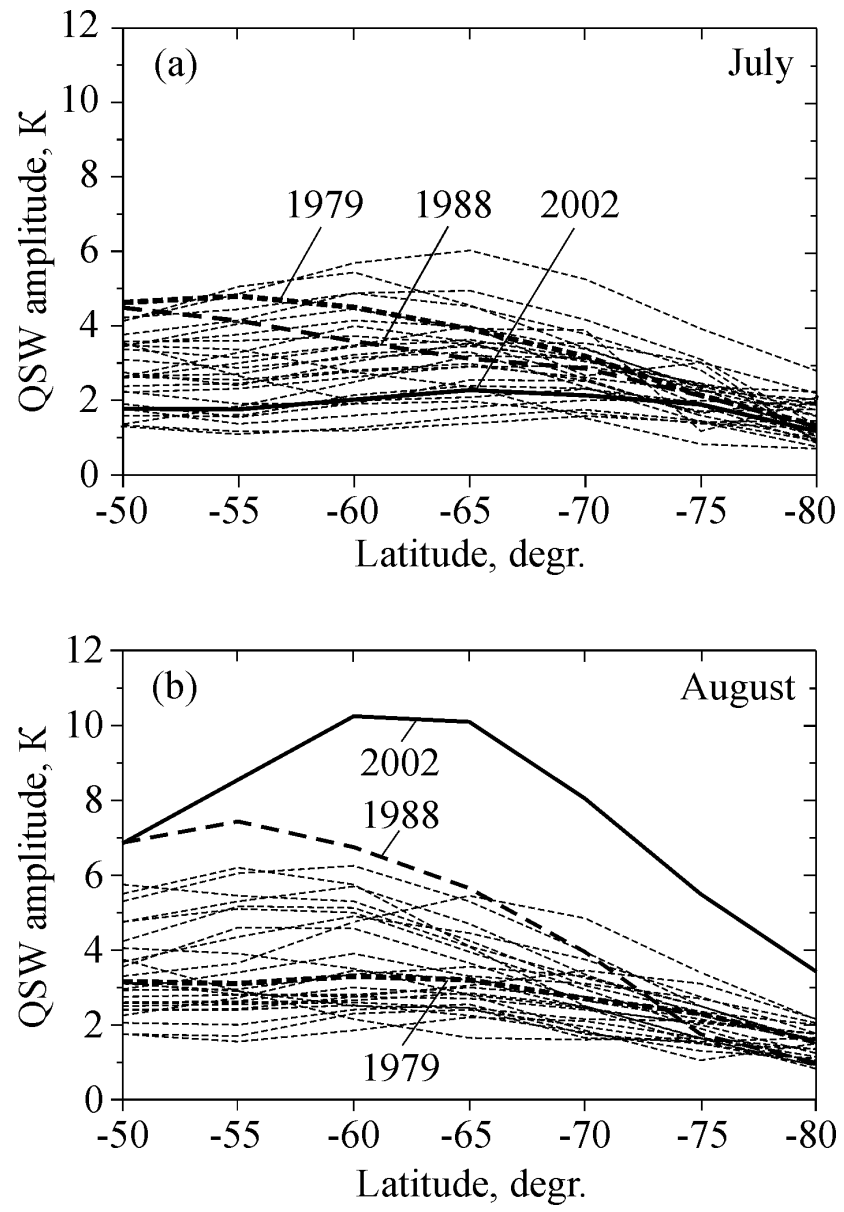

Fig. 6. Interannual variations of the latitudinal distribution of the stationary wave amplitude in the stratosphere temperature at pressure level $100 \mathrm{hPa}$ in (a) July and (b) August 1979-2006. The two years of anomalously small ozone hole are marked by thick dashed line for 1988 (large warming) and thick solid line for 2002 (major warming). The pre-ozone hole year 1979 is marked by short-dashed thick lines.

The second similar feature in the warmings of 1988 and 2002 is the westward displacement of the quasi-stationary zonal wave in the spring total ozone distribution. Because the QSW-1 dominates in the Antarctic region this tendency appears in wave ridge and trough displacement. In 1988, both extremes shifted westward by $55^{\circ}$, on average, relative to the strong vortex situation in 1987 (Fig. 2a). This yields a corresponding counterclockwise displacement of the zonal asymmetry axis. In 2002, as distinct from 1988, the wave trough only undergoes the significant westward shift by $70^{\circ}$ relative to 2001 (Fig. 2b).

We have shown in Grytsai et al. (2007) that a longitudinal position of the QSW minimum is affected strongly by the relationship between the QSW-1 and QSW-2 phases and amplitudes. Concerning the results presented in Fig. 2, it could be assumed that the warmings of 1988 and 2002 differed by amplitudes and phases of these harmonics. In general, 
westward displacement of the QSW extremes is associated with the weaker zonal wind, as, under the stronger westerly wind conditions, the QSW ridge and trough's positions can locate preferably far to the east. A comparison of the zonal asymmetry in the total ozone (Fig. 2) and zonal wind velocity at $30 \mathrm{hPa}$ (Fig. 3) shows a coordinated westward shift of their zonal anomalies under a weaker vortex condition. It was assumed in Sect. 4 that the total ozone asymmetry could be determined by the wind asymmetry at the middle stratosphere altitudes. It is possible that, at the descent branch of the meridional Brewer-Dobson circulation, ozone is redistributed in a zonal direction due to zonal asymmetry in the wind velocity (Fig. 4). This can explain the total ozone and wind velocity anti-correlation in their longitudinal distributions (Figs. 2 and 3).

The tendency to recover the pre-1980s zonal structure is seen in both anomalous warmings (Fig. 2). In particular, the QSW ridge and trough positions on the thick (1988 and 2002) lines are close to those on the dashed (1979) lines in Fig. 2. A similar behavior was noted above in the TOC zonal mean, too. One can conclude that the two "anomalous" events in the southern stratosphere during the last decades look closer to "normal" compared with the stratosphere state observed before the 1980s. However, this "normality" was provided by atypical dynamical activity.

As seen from recent studies, a blocking event in the South Atlantic and strong upward wave propagation were critical to the occurrence of the major warming in late September 2002 (Nishii and Nakamura, 2004; Manney et al., 2005; Allen et al., 2006). Results of our work show that some indications of the anomalous warming in the southern stratosphere appear in the total ozone and lower stratosphere temperature data since August. The TOC zonal mean at $65^{\circ} \mathrm{S}$ in Fig. 1b (thick line) demonstrates that the anomalously high total ozone level was established in August and the first half of September 2002, that predetermined, to a certain extent, the spring ozone anomaly occurrence at this latitude.

An evident increase in the TOC zonal mean at the vortex edge region in August 2002 (Fig. 1) is accompanied by the significant increase in the QSW amplitude at the same latitudes $\left(60^{\circ} \mathrm{S}-65^{\circ} \mathrm{S}\right.$, Fig. $\left.6 \mathrm{~b}\right)$, preceding the major warming 2002. The latter feature is observed in the lower stratosphere temperature at the pressure level of $100 \mathrm{hPa}$. The distinction between 1988 and 2002 in the QSW amplitude level and distribution with latitude can indicate that an increase not only in temperature but also in the QSW intensity at the vortex edge precedes the anomalous warming. Quantitative estimations show that the amplitude level of $10 \mathrm{~K}$ in the vortex edge region observed in August 2002 (Fig. 6b) preceded the major warming in September by one month. The lower peak value of the QSW amplitude $(\sim 7 \mathrm{~K})$ and its lower latitude $\left(55^{\circ} \mathrm{S}\right)$ in August 1988 were perhaps not favorable conditions for the major warming in the next months. These results suggest that the quasi-stationary planetary wave influences noticeably the southern polar vortex.
Acknowledgements. NCEP Reanalysis data on stratosphere temperature provided by the NOAA-CIRES Climate Diagnostics Center, Boulder, Colorado, USA, from their Web site at http://www.cdc. noaa.gov. Total ozone data from the TOMS measurements had been obtained via the NASA Web site http://toms.gsfc.nasa.gov. This research was partly made in the framework of the SCAR ICESTAR Program. The work was partly supported by National Taras Shevchenko University of Kyiv, project 06BF051-12, by Grant of Ministry Education and Science of Ukraine: GreeceUkraine M/86-2006. Authors thank the anonymous referees for a number of their useful comments and corrections.

Topical Editor U.-P. Hoppe thanks two anonymous referees for their help in evaluating this paper.

\section{References}

Allen, D. R., Bevilacqua, R. M., Nedoluha, G. E., Randall, C. E., and Manney, G. L.: Unusual stratospheric transport and mixing during the 2002 Antarctic winter, Geophys. Res. Lett., 30, 1599, doi:10.1029/2003GL017117, 2003.

Allen, D. R., Coy, L., Eckermann, S. D., McCormack, J. P., Manney, G. L., Hogan, T. F., and Kim, Y.-J.: NOGAPS-ALPHA simulations of the 2002 Southern Hemisphere stratospheric major warming, Mon. Wea. Rev., 134, 498-518, 2006.

Baldwin, M., Hirooka, T., O’Neill, A., and Yoden, S.: Major stratospheric warming in the Southern Hemisphere in 2002: dynamical aspects of the ozone hole split, SPARC Newsletter, 20, 24-26, 2003.

Charlton, A. J., O'Neill, A., Lahoz, W. A., and Berrisford, P.: The splitting of the stratospheric polar vortex in the Southern Hemisphere, September 2002: dynamical evolution, J. Atmos. Sci., 62, 590-602, 2005.

Grytsai, A. V.: Antarctic total ozone anomaly during 1988 and 2002 springs, Ukrainian Antarctic Journal, 3, 10-18, 2005.

Grytsai, A., Grytsai, Z., Evtushevsky, A., and Milinevsky G.: Interannual variability of planetary waves in the ozone layer at $65^{\circ} \mathrm{S}$, Int. J. Rem. Sens., 26, 3377-3387, 2005.

Grytsai, A. V., Evtushevsky, O. M., Agapitov, O. V., Klekociuk, A. R., and Milinevsky, G. P.: Structure and long-term change of the zonal asymmetry in Antarctic total ozone during spring, Ann. Geophys., 25, 361-374, 2007, http://www.ann-geophys.net/25/361/2007/.

Hio, Y. and Yoden, S.: Interannual variations of the seasonal march in the Southern Hemisphere stratosphere for 1979-2002 and characterization of the unprecedented year 2002, J. Atmos. Sci., 62, 567-580, 2005.

Hoppel, K., Bevilacqua, R., Allen, D., Nedoluha, G., and Randall, C.: POAM III observation of the anomalous 2002 Antarctic ozone hole, Geophys. Res. Lett., 30, 1394, doi:10.1029/2003GL016899, 2003.

Jadin, E. A. and Vargin, P. N.: Antarctic ozone hole in 2002 and SST anomalies in the South Oceans, Proc. Quadr. Ozone Symp., 1-8 June 2004, Kos, Greece, 2, 1033-1034, 2004.

Kallberg, P., Berrisford, P., Hoskins, B., Simmons, A., Uppala, S., Lamy-Thepaut, S., and Hine, R.: ERA-40 Atlas, ERA-40 Project Report Series No. 19, European Centre for Medium Range Weather Forecasts, England, UK, 191 p., 2005.

Kanzawa, H. and Kawaguchi, S.: Large stratospheric sudden warming in Antarctic winter and shallow ozone hole in 1988, Geophys. 
Res. Lett., 17, 77-80, 1990.

Krüger, K., Naujokat, B., and Labitzke, K.: The unusual midwinter warming in the Southern Hemisphere stratosphere 2002: a comparison to Northern Hemisphere phenomena, J. Atmos. Sci., 62, 603-613, 2005.

Manney, G. L., Sabutis, J. L., Allen, D. R., Lahoz, W. A., Scaife, A. A., Randall, C. E., Pawson, S., Naujokat, B., and Swinbank, R.: Simulations of dynamics and transport during the September 2002 Antarctic major warming, J. Atmos. Sci., 62, 690-707, 2005.

Newman, P. A. and Nash, E. R.: The unusual Southern Hemisphere stratosphere winter of 2002, J. Atmos. Sci., 62, 614-628, 2005.

Nishii, K. and Nakamura, H.: Tropospheric influence on the diminished Antarctic ozone hole in September 2002, Geophys. Res. Lett., 31, L16103, doi:10.1029/2004GL019532, 2004.

Quintanar, A. I. and Mechoso, C. R.: Quasi-stationary waves in the Southern Hemisphere, Part I: Observational data, J. Climate, 8, 2659-2672, 1995.

Randall, C. E., Manney, G. L., Allen, D. R., Bevilacqua, R. M., Hornstein, J., Trepte, C., Lahoz, W., Ajtic, J., and Bodeker, G.: Reconstruction and simulation of stratospheric ozone distributions during the 2002 austral winter, J. Atmos. Sci., 62, 748-764, 2005.
Scaife, A. A., Jackson, D. R., Swinbank, R., Butchart, N., Thornton, H. E., Keil, M., and Henderson, L.: Stratospheric vacillations and the major warming over Antarctica in 2002, J. Atmos. Sci., 62, 629-639, 2005.

Stolarski, R. S., McPeters, R. D., and Newman, P. A.: The ozone hole of 2002 as measured by TOMS, J. Atmos. Sci., 62, 716-720, 2005.

Varotsos, C.: The Southern Hemisphere ozone hole split in 2002, Environ. Sci. Pollut. R., 9, 375-376, 2002.

Varotsos, C.: What is the lesson from the unprecedented event over Antarctica in 2002?, Environ. Sci. Pollut. R., 10, 80-81, 2003 a.

Varotsos, C.: Why did a "no-ozone-hole" episode occur in Antarctica?, EOS Transactions, 84(19), 183, 2003b.

Varotsos, C.: The extraordinary events of the major, sudden stratospheric warming, the diminutive Antarctic ozone hole, and its split in 2002, Environ. Sci. Pollut. R., 11, 405-411, 2004.

Wirth, V.: Quasi-stationary planetary waves in total ozone and their correlation with lower stratospheric temperature, J. Geophys. Res., 98, 8873-8882, 1993.

WMO (World Meteorological Organization): Scientific assessment of ozone depletion: 1998, Report No. 44, Geneva, 1999. 